
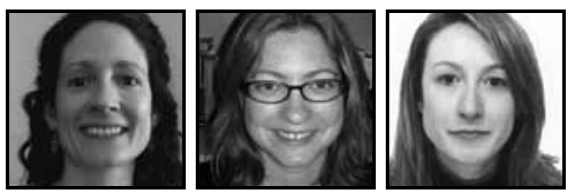

\title{
Creative Literacies and Learning With Latino Emergent Bilinguals
}

\author{
Patricia Martínez-Álvarez, Teachers College, Columbia University \\ María Paula Ghiso, Teachers College, Columbia University \\ Isabel Martínez, Autónoma University of Madrid
}

\section{ABSTRACT}

Research documents the benefits of implementing pedagogical practices that foster creativity in order to prepare students for a changing future and to meet the needs of emergent bilingual learners. Designing pedagogical invitations that make room for creativity is especially urgent given educational policies in the United States which privilege decontextualized, standardized learning aimed at "testable" skills, often in opposition to more expansive multilingual and multimodal learning opportunities. The current study explores how multimodal literacy experiences grounded in bilingual learners' sociocultural realities stimulated creativity and allowed students to demonstrate and practice their creative abilities.

\section{Introduction}

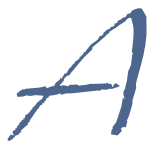

s bilingual, former Spanish-English elementary teachers, we remember having space during the year to explore creative opportunities for teaching and learning. In the last decade, The No Child Left Behind (NCLB) era in the United States has pushed schools to prioritize test results, and by extension, test preparation, over culturally responsive and transformative learning experiences that invite students to be designers (Kress, 2003) rather than passive recipients of knowledge. This shift in policy and practice is limiting opportunities for more creative, and potentially more engaging, modes of learning and of expressing what is learned, 
many of which are not measurable through test performance. As a result, students are often ushered into an artificial curriculum that does not respect their diverse profiles.

Research documents how this shift has disproportionately affected students from historically minoritized populations, such as language learners and children living in poverty (Menken, 2008), as many families with privilege opt out of neighborhood schools towards private or more pedagogically progressive contexts, and schools labeled as "failing" - overwhelmingly those that serve students of coloradopt remedial curricula in an effort to raise test scores. This has been the case for the students with whom we work: first graders in a Spanish-English bilingual program whose families are primarily Latin American immigrants. As a result of the growth of Latino students in U.S. public schools, there is an impetus on studying the educational progress of this population. The focus, however, has been on making conclusions based on standardized assessments, which solely measure basic knowledge and skills and too often document student failure rather than create opportunities for academic success.

Practices focused on factual learning for immediate higher test performance restrict students who are acquiring multiple languages-henceforth referred to as emergent bilinguals (García \& Kleifgen, 2010)—who tend to perform better than monolinguals in measures of divergent thinking, or creativity (Ricciardelli, 1992; Hommel, Colzato, Fischer, \& Christoffels, 2011; Okoh, 1980, cited in Kharkhurin, 2007), and who benefit from pedagogies which are personalized and employ multiple modes for learning (e.g., hands-on, visual, and kinesthetic). Insisting on teaching with the primary objective of passing a test is privileging some learners while failing those who don't fit within the social/academic U.S. norm.

This manuscript documents students' engagement with a technologymediated biliteracy pedagogy that valued students' cultural and linguistic funds of knowledge (Moll, Amanti, Neff, \& González, 1992) and sought to create instructional Third Spaces (Gutiérrez, 2008) that blended home and school. Drawing on notions of the multiple literacies needed for an increasingly technological and global future, our pedagogy did not ask students to replicate a teacher-directed model of writing, as is the case with many standardized curricula, but to intentionally utilize varied available resources, including multiple modes of representation, for actively designing (Kress, 2003) texts along student-generated purposes.

We found that as a result of participating in these pedagogical invitations, first grade Spanish-English bilingual learners created written products that 
demonstrated enhanced creativity. Based on Irby and Lara-Alecio's (1996) characteristics of Latino bilingual gifted students and Kharkhurin's (2010) investigation on bilingual nonverbal creative behavior, we define creativity in student writing in terms of: (1) Complexity in format by integrating imagery, text, and add-ons (i.e., sticky notes or pieces of paper); (2) Richness of Imagery demarcated by number of elements (i.e., contexts and/or people); (3) Richness of Text which refers to multiple contexts or scenarios expressed through writing; (4) Amount of Text; and (5) Expressions of Feelings and Emotions. Below, we detail the theoretical frameworks of language and literacy learning that inform this work, and go on to examine creativity in student writings as informed by our study.

\section{Conceptual Frameworks}

There is consensus in the educational literature about the need to better serve the growing language-learning population across the United States (García, 2001; Darder, 1995; Flores, Tefft-Cousin, \& Díaz, 1991). The increasing focus of such pedagogies, however, has often promoted acquisition of English at the expense of the native language. Literacy policies in particular have resulted in top-down curricula that emphasize decontextualized skills, rather than valuing literacy as a process of interaction that is not merely cognitive (Scribner \& Cole, 1981).

Conflicting with such skills-based curricula, there is a long-standing body of research that documents children's engagement with literacy in ways that draw on out-of-school practices, community heritages, and cultural and linguistic resources (e.g., Campano, 2007), including use of multimodality (Siegel, 2012) and new technologies. Thus, literacy is not merely textual decoding but also the transmission of and participation in cultural events mediated through symbolic artifacts and language (Cummins, 2004; Dixon-Krauss, 1996; Vygotsky, 1997). Emerging research in the area of biliteracy provides windows into language arts practices that aim to develop more linguistically inclusive pedagogies (Franquiz \& de la Luz Reyes, 1998; Medina \& Campano, 2006). This includes literacy programs that foster a sense of shared power between teachers, students', and families, in which learners' cultures and home languages are valued (Cummins, 2004).

Our work brings together social practice theories of literacy as a process of participating in communities of practice (Lave \& Wenger, 1991) within hierarchies of power (Freire, 1973; Street, 1995) with community and family funds of knowledge 
(Moll, 1992) to create school opportunities for learning based on students' cultural and linguistic resources-making the instructional context a hybrid Third Space (Gutiérrez, 2008). This perspective draws on frameworks that conceptualize learning as a dialectic between collective and individual activities and sense-making (Engeström \& Sannino, 2010) across a range of contexts, and whereby contradictions and tensions are not barriers but the source of new "expansive learning" (Engeström, 1987). The current friction between curricula geared to a testing model and students' family and community knowledge may, through biliteracy pedagogies such as the engagements we feature in this article, present opportunities for expanded teaching and learning that recognizes emergent bilinguals' funds of knowledge. We focus here in one of our findings: that such pedagogical invitations foster bilingual students' creativity.

\section{Relevance of Creativity in Education}

The rapidly changing nature of our society has implications for the kinds of proficiencies that will be necessary for a 21 st century work force. Creativity may contribute to the advancement of science, mathematics, arts, and technology, and could fortify individuals' ability to problem-solve and adapt. According to Aljughaiman and Ayoub (2012), "creative ability is of great importance in the economic growth and development of emerging regions" (p. 159). Thus, education that fosters creativity supports students in meeting the unpredictable demands of their future reality (NACCCE, 1999), provides teachers with more opportunities to support and assess diverse learners (Antink Meyer, 2012), and impacts critical-thinking skills, motivation, and engagement (Amabile, 1998; Eyster, 2010; Lederman, 2007).

Pedagogically, creativity becomes especially important in the language classroom (Akinwamide \& Adedara, 2012). Akinwamide (2007) enumerates seven dimensions of the connection between language learning and creativity: 1) Language is generative and results in creativity; 2) Creativity triggers learning; 3) Some people become motivated as a result of inspiration which makes them create something of value; 4) Creativity improves self-esteem; 5) Creative work in the language classroom can lead to authentic communication and cooperation; 6) Creative tasks enrich classroom work; and 7) Creative thinking is an important skill in real life. Despite its importance for the education of all students, but particularly as a key stimulus for academic growth for emergent bilinguals, creativity has not been well represented as a topic in bilingual education research, and does not hold a significant position in educational practice (Boden, 2001). 
There is some research documenting the relationship between pedagogy and creativity. For example, Aljughaiman and Ayoub (2012) studied the effects of an enrichment program with three units on upper elementary gifted students' creativity. During their enrichment program, which lasted six weeks, students were exposed to a problem-based theme and created a project of their choice in groups (e.g., research paper, website, and video). The study resulted in significantly enhanced analytical and creative abilities in the experimental group in comparison to a control group. Geissler, Edison, and Wayland (2012) found that an instructional intervention improved college students' ability to engage in creative discussions. Fleta Guillen and García Bermejo (2011) document pedagogies that promote language, content, and literacy in English by stimulating the creativity of the learner through the arts. Rather than measuring creativity per se, the authors asked students to use their creativity in movement and music for telling stories, and concluded that these stories were means of internalizing language and literacy growth.

Research shows that bilinguals have enhanced creativity when compared to monolinguals (Ricciardelli, 1992), with the bilingual practice influencing the underlying processes and mechanisms of creativity (Hommel et al., 2011). The sociocultural environment-learner's home and community experiences_-plays a key role in this process of creative and divergent thinking (Kharkhurin, 2010). Our instruction sought to capitalize on these home resources for learning within school contexts.

Our review of the literature indicates the benefit of implementing pedagogical practices fostering creativity both for preparing students for a changing future and for better meeting the linguistic and learning needs of emergent bilingual learners. The current study explores how literacy experiences grounded in bilingual learners' sociocultural realities stimulated creativity and allowed students to demonstrate and practice their creative abilities.

\section{Research Questions}

In order to explore bilingual students' creativity in the literacy classroom, we grounded our work in the following guiding questions:

1. Will an instructional sequence involving expansive literacy activities grounded in learners' sociocultural realities and mediated by technology result in first grade bilingual students' enhanced creative performance in writing samples? 
2. What are the distinguishing characteristics of creative written products bilingual students generate when invited to share their home and community experiences orally and visually?

\section{Methodology}

\section{Participants}

The contexts for the study are two public elementary schools in a large Northeastern city. A total of 93 first graders participated in this study. Fifty-four children participated in the instructional sequence (27 and 27 in each of the two classes respectively). Fifty-three of these children identified as Latino, and all received free lunch. Due to absences, only 48 were included in the quantitative analysis we feature in this article. The majority of the children's families, and many of the children themselves, were immigrants from Latin America. The dual language program functioned on alternating days according to language. The Spanish teacher was bilingual; the English teacher did not speak Spanish, but showed a resource orientation to the children's native languages and an appreciation and understanding for Latino culture. Both planned collaboratively and were highly regarded at the school.

In addition, 37 bilingual students were in the control group (two classes with 18 and 19 students each). Thirty-five identified as Latino, and three spoke both Spanish and Mixteco, an indigenous Mexican language. Thirty-five participants received free or reduced lunch. Due to absences, only 28 students were included in the control group for the quantitative analysis we feature in this article. This school followed a rollercoaster dual language model, switching English and Spanish instruction daily while alternating language mornings and afternoons. The Spanish and English teachers met the same characteristics as those in the instructional group.

\section{Biliteracy Pedagogies Procedure}

For one semester, we met biweekly with the students and teachers in our study around a series of writing experiences that extended beyond print text to multiple modes and media (Kress, 2003) for representation. The biliteracy activities were designed to tap into students' creative, linguistic, cultural, and experiential resources, and were mediated by the use of the cameras to document their families' and communities' daily experiences. Our intention was also to shift agency from teachers to students regarding what counts as literacy and is worth telling in a school setting. 
To engage students in the proposed biliteracy pedagogies, we asked them to utilize low-cost digital cameras to document: 1 ) their family meals and daily activities; and 2) their community experiences. As children brought their photographs to school, they generated oral stories around the photographs in small groups. From these oral narratives, they decided which visual texts they wanted to print out. These selections became the basis for writing using a variety of formats and themes.

The multi-modal composing consisted of: 1) Writing down stories based on the self-selected images; 2) Creating digital comics using Comic Life software and writing the dialogue and captions for each element in the sequence; 3) Drawing paper-based comics documenting their immigrant stories and family/community experiences; 4) Using talk and thought bubbles to render the perspectives of different figures in an image; and 5) Creating a Collage of my Worlds using photographs, labels, and art materials to write, draw, and symbolically represent their culturally and linguistically hybrid worlds.

Throughout, we intentionally emphasized to children that they could utilize any or all of their languages to communicate their stories, both orally and in writing. We also focused on multiple ways of conveying meaning beyond language, in particular through the use of visuals such as drawing. The implicit message students received was that their stories were worth communicating in school and were appropriate themes for rigorous academic tasks.

Children's work was bounded in a book and shared with teachers, researchers, classmates, and parents in a final celebration. Children took digital copies of their photographs and the book home and they were encouraged to read it and share it, and to continue to add to it over the summer. Before and after the biliteracy curriculum, children were asked to write a story about their families and were given unlimited pieces of blank white paper to create their stories. No further instructions or materials were provided.

\section{Data Collection}

This is a mixed-methods study blending ethnographic and participatory approaches with quasi-experimental quantitative design. Our aim in combining qualitative and quantitative data was to triangulate findings and provide a more robust understanding of our research question (Denzin, 1978) regarding the effects of multimodal biliteracy pedagogies as well as students' negotiation of such curricular invitations. The purpose of a quasi-experimental design is to test descriptive 
causal hypotheses about identified manipulable variables. Quasi-experiments do not traditionally employ random assignment (Campbell \& Stanley, 1963). The qualitative (Erickson, 1986) and practitioner research (Cochran-Smith \& Lytle, 2009) component of the study documents how students engaged with the multimodal literacy experiences we designed and facilitated.

Data sources for the project include: 1) Pre- and post-writing samples asking students to draw and write a story about their family; 2) Children's written products (i.e., digital texts, comics, collage); 3) Audio-recorded and transcribed class sessions, group interactions, and children's discussions of their photographs; 4) Fieldnotes and researcher reflective memos; and 5) Interviews with the teachers and students.

\section{Data Analysis}

We analyzed the qualitative data thematically in a recursive and iterative process (Strauss \& Corbin, 1998), identifying patterns both in the content of children's works, as well as in the process by which children engaged in composing stories. For the quantitative analysis reported on in this article, we focused specifically on students' pre and post bilingual writing samples.

The quantitative analysis followed several steps. First, the authors read all the writing samples to extract outstanding trends in the data. Then, in an effort to avoid the use of standardized test results that fail to fully portrait bilingual students' creative abilities, and based on the literature on the measurement of creativity, we identified several elements applicable to analyzing creativity in children's writing and drawing. We designed a creativity rubric as a lens to more systematically examine children's work. The development of the creativity rubric was informed primarily by two reports on gifted/creative characteristics particular to bilingual learners. One is Irby and Lara-Alecio's (1996) work identifying 11 characteristics of Latino bilingual gifted students. Among these characteristics, they include strong cultural sensitivity and familial connections, preference for collaboration, creative performance, and elaborate imagination exhibited through oral and written language and rich imagery. The second is Kharkhurin's (2010) investigation of bilingual verbal and nonverbal creative behavior based on college students who had emigrated from the former Soviet Union and spoke both Russian and English. Kharkhurin identified five verbal and 10 nonverbal criterion-referenced creativity indicators using the standard ATTA assessment procedure (Goff \& Torrance, 2002). The identified nonverbal indicators were: 1) Richness and colorfulness of imagery; 2) Expressions of feelings and emotions; 3 ) Future orientation; 4) Humor: conceptual incongruity; 5) Provocative questions; 6) 
Abstractness of titles; 7) Context; 8) Synthesis of two or more figures; 9) Internal visual perspective; and 10) Fantasy. These indicators informed the conception of the creativity rubric in the present study. The resulting rubric included five elements and is shown in Figure 1.

\begin{tabular}{|l|l|l|l|l|}
\hline $\begin{array}{l}\text { Creativity } \\
\text { Characteristics }\end{array}$ & 0 Points & $\mathbf{1}$ Point & 2 Points & 3 Points \\
\hline $\begin{array}{l}\text { Complexity } \\
\text { (format, imagery, } \\
\text { and/or text) }\end{array}$ & $\begin{array}{l}\text { No images or } \\
\text { text }\end{array}$ & $\begin{array}{l}\text { Only images or } \\
\text { text with no add- } \\
\text { ons (i.e. glued } \\
\text { pieces of paper, } \\
\text { cut out bubbles) }\end{array}$ & $\begin{array}{l}\text { Imagery \& text } \\
\text { but separated }\end{array}$ & $\begin{array}{l}\text { Integrates 2 modes of } \\
\text { representation: Imagery } \\
\text { with text } \\
\text { or includes adds-on to } \\
\text { product (i.e. comic) }\end{array}$ \\
\hline $\begin{array}{l}\text { Richness of } \\
\text { Imagery (number } \\
\text { of elements, e.g. } \\
\text { contexts \& people) }\end{array}$ & No images & $\begin{array}{l}1-2 \text { elements on } \\
\text { image }\end{array}$ & $\begin{array}{l}\text { 3-10 elements } \\
\text { on image }\end{array}$ & $\begin{array}{l}\text { > 10 elements on image } \\
\text { or inclusion of multiple } \\
\text { contexts (i. e. several } \\
\text { consecutive drawings) }\end{array}$ \\
\hline $\begin{array}{l}\text { Richness of Text } \\
\text { No words }\end{array}$ & $\begin{array}{l}\text { Text describes } \\
\text { one context } \\
\text { (scenario, e.g. } \\
\text { park) }\end{array}$ & $\begin{array}{l}\text { Two contexts } \\
\text { (scenarios, e.g. } \\
\text { Park and home) }\end{array}$ & $\begin{array}{l}\text { More than 2 contexts } \\
\text { (scenarios) with } \\
\text { elaboration (e.g. } \\
\text { describing what } \\
\text { happens in street, then } \\
\text { home, \& then park) }\end{array}$ \\
\hline Amount of Text & No words & Up to 30 words & 31-50 words & $>50$ words \\
\hline $\begin{array}{l}\text { Expressions of } \\
\text { Feelings and } \\
\text { Emotions }\end{array}$ & $\begin{array}{l}\text { No reference } \\
\text { to feelings }\end{array}$ & $\begin{array}{l}1 \text { reference to } \\
\text { feelings }\end{array}$ & $\begin{array}{l}\text { 2 references to } \\
\text { different } \\
\text { feelings }\end{array}$ & 3 references to feelings \\
\hline
\end{tabular}

Fig. 1: Creativity rubric

Two raters who were bilingual in Spanish and English assessed the writing pieces' creative characteristics using the rubric. A total of five different scores (Complexity, Richness of Imagery, Richness of Text, Amount of Text, and Expressions of Feelings and Emotions) were obtained for each pre- and post-writing sample. One of the authors scored all the samples, while a second reviewer scored $38 \%$ of the products. According to Kennedy (2005), the current convention is that $20 \%$ is a minimal baseline and $33 \%$ is preferable for adequately assessing the consistency of measurement. Using Kappa coefficients (Cohen, 1960), the inter-rater reliabilities obtained were between .71 and 1.00. Landis and Koch (1977) characterized values .61-.80 as substantial. Nonetheless, to improve inter-rater reliability, cases of disagreement were discussed until an agreement was reached.

Prior to performing the statistical analyses, the scores in each characteristic of creativity for the writing samples students wrote before the instructional sequence in both instructional and control groups were compared to determine if the groups' levels differed significantly. One-way between groups' analysis of variance was used 
to determine initial differences between the two sets of scores. As shown in Table 1, there was a statistically significant difference between the instructional and the control groups on pre-instruction scores on students' writing samples for the scores in all five characteristics of creativity.

\section{Table 1}

Pre-instruction ANOVA Means From Treatment and Control

\begin{tabular}{|c|c|c|}
\hline CHARACTERISTICS & $F$ & $d f$ \\
\hline Complexity & $4.43^{*}$ & $(1,74)$ \\
\hline Richness of Imagery & $6.71^{*}$ & $(1,74)$ \\
\hline Richness of Text & $15.74^{* * *}$ & $(1,74)$ \\
\hline Amount of Text & $75.75^{* * *}$ & $(1,74)$ \\
\hline Expression of Feelings \& Emotions & $5.23^{*}$ & $(1,74)$ \\
\hline
\end{tabular}

${ }^{*} p<.05^{* *} p<.01 .^{* * *} p<.001$

Consequently, a one-way between groups' analysis of covariance was conducted on the pre- and post-creativity scores from students in the instructional and control groups. The independent variable used was the group students belonged to (instructional or control) and the dependent variable was students' scores in the five creativity criteria after the instructional sequence. Participants' pre-instruction scores were used as the covariate in this analysis.

\section{Findings}

Table 2 presents the post-instructional group's means and standard deviations for the different characteristics of creativity. 
Table 2

Means and Standard Deviations for Pre- and Post-Dependent Measures

\begin{tabular}{|c|c|c|c|c|c|c|c|c|}
\hline \multirow{3}{*}{ CHARACTERISTICS } & \multicolumn{4}{|c|}{$M$} & \multicolumn{4}{|c|}{ SD } \\
\hline & \multicolumn{2}{|c|}{$\begin{array}{l}\text { INSTRUCTIONAL } \\
\mathrm{N}=48\end{array}$} & \multicolumn{2}{|c|}{$\begin{array}{l}\text { CONTROL } \\
\mathrm{N}=\mathbf{2 8}\end{array}$} & \multicolumn{2}{|c|}{$\begin{array}{l}\text { INSTRUCTIONAL } \\
\mathrm{N}=48\end{array}$} & \multicolumn{2}{|c|}{$\begin{array}{l}\text { CONTROL } \\
\mathrm{N}=\mathbf{2 8}\end{array}$} \\
\hline & Pre & Post & Pre & Post & Pre & Post & Pre & Post \\
\hline Complexity & $1.90^{*}$ & 2.08 & 1.64 & 1.57 & .42 & .71 & .62 & .50 \\
\hline Richness of Imagery & 1.85 & 1.92 & 1.25 & 1.04 & .80 & 1.13 & 1.24 & .96 \\
\hline Richness of Text & 1.19 & 1.81 & 1.82 & 1.61 & .61 & .84 & .77 & .83 \\
\hline Amount of Text & 1.38 & 2.15 & 2.68 & 2.21 & .67 & .82 & .55 & .83 \\
\hline $\begin{array}{l}\text { Expression of Feelings } \\
\text { \& Emotions }\end{array}$ & .48 & .73 & .96 & .93 & .65 & .94 & 1.20 & 1.15 \\
\hline
\end{tabular}

The results of the analysis of covariance, adjusted for pre-instruction scores in the characteristics of creativity are shown in Table 3, and illustrated in Figure 2. These results reveal that there was a statistically significant difference between the instructional and control groups on post-instruction scores in four of the five characteristics. Namely, the statistically significant differences were in: Complexity, Richness of Imagery, Richness of Text, and Amount of Text. Once again, all effect sizes were small according to Cohen's (1960) guidelines.

\section{Table 3}

ANCOVAS' Results Comparing the Post-Instruction Means of the Two Groups

\begin{tabular}{lc|l|c|} 
CHARACTERISTICS & $F$ & $d f$ & $d f$ \\
Complexity & $7.32^{* * *}$ & $(1,73)$ & .23 \\
\hline Richness of Imagery & $6.94^{* *}$ & $(1,73)$ & .09 \\
\hline Richness of Text & $4.07^{*}$ & $(1,73)$ & .05 \\
\hline Amount of Text & $11.46^{* *}$ & $(1,73)$ & .14 \\
\hline Expression of Feelings \& Emotions & 0.06 & $(1,73)$ & .001
\end{tabular}

${ }^{*} \mathrm{p}<.05^{* *} \mathrm{p}<.01 .^{* * *} \mathrm{p}<.001$ 
The changes that took place for each characteristic from pre to post the instructional sequence are best illustrated in Figure 2.

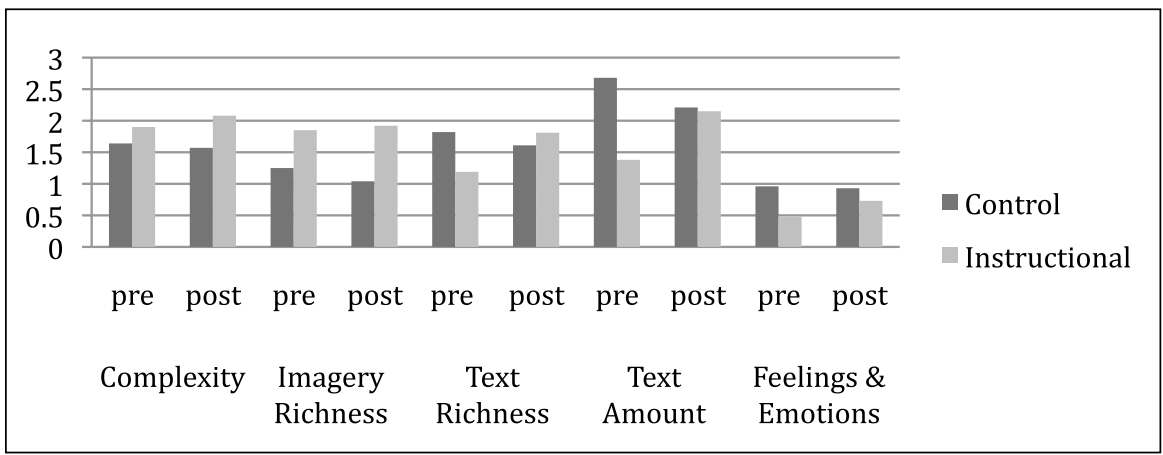

Fig. 2: Pre/post results for creativity characteristics

As can be seen in Table 3, the change in the Expression of Feelings and Emotions category was not statistically significant. When looking at the frequency of occurrence, children in the instructional group included feelings and emotions in their pre-instruction writing samples in 24 cases and 39 cases during the postinstruction. On the other hand, the frequency of occurrence in the pre-instruction writing for children in the control group was 34 instances, versus 26 in the post. These results show that, even though the changes were not significant statistically, children in the instructional group added more feelings to their writing pieces as a result of the instructional sequence, while children in the control group actually reduced the number of references to feelings and emotions.

Therefore, quantitative analysis confirms that the instructional sequence involving expansive literacy activities grounded in learners' sociocultural realities and mediated by technology resulted in first grade bilingual students' enhanced creative performance in writing samples for at least four of the identified characteristics. Amount of Text is the characteristic most impacted by the instruction, and Expression of Feelings and Emotions the least.

The qualitative analysis supports these findings and adds information to address our second research question. We identified several distinguishing characteristics of creative written products bilingual students generated after participating in these instructional invitations, which we describe in the section that follows through examples of student work. 


\section{Illustrative Examples}

Our qualitative analysis confirmed that, at the end of the instructional sequence, participating children's work showed enhanced creativity in terms of Complexity, Richness of Imagery, Richness of Text, Amount of Text, and Expression of Feelings and Emotions when compared to the non-participating group. To illustrate this, we first present a representative example from Juan, a student in the control group.

\section{Juan}

Juan's pre-writing is shown in Figure 3 and his post-writing is in Figure 4.

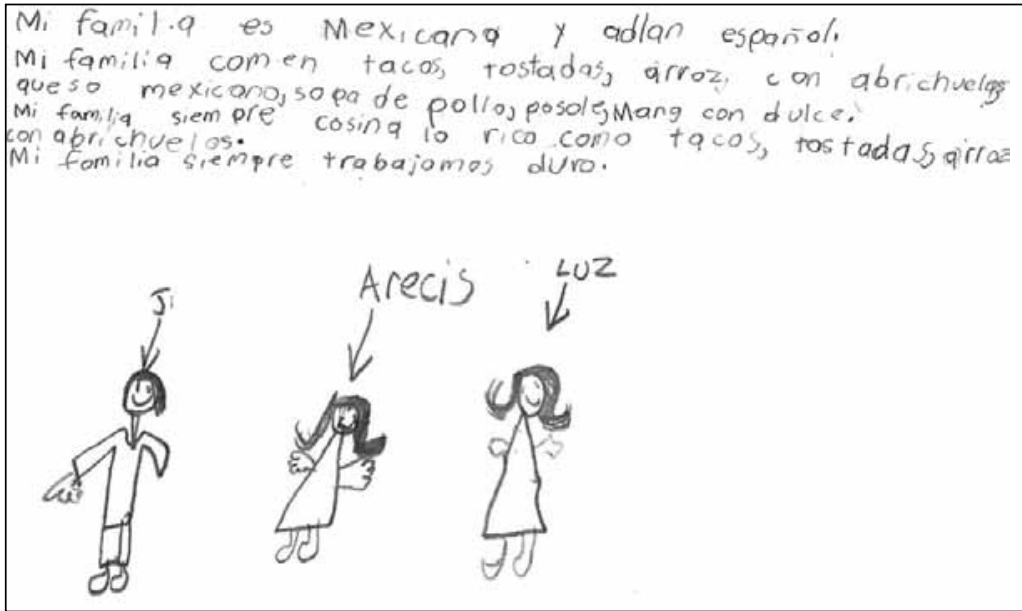

Fig. 3: Juan's pre-instruction writing

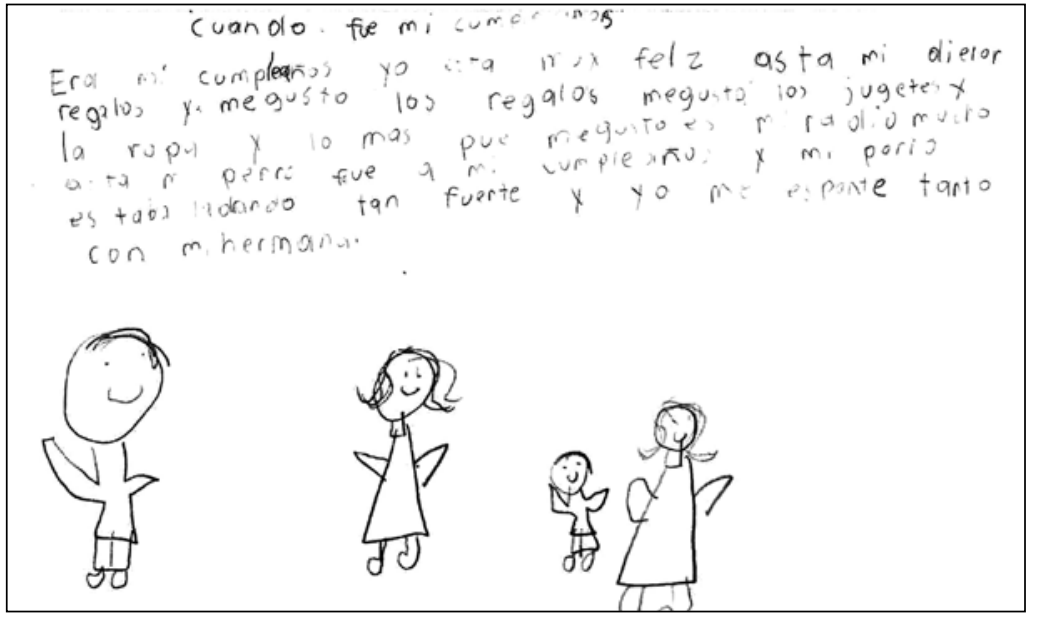

Fig. 4: Juan's post-instruction writing 
A few differences from analyzing Juan's pre to post products can be identified, but these are not directly related to the creativity indicators. One difference is that in the post-writing experience the student wrote a title "cuando fue mi cumpleaños" [when it was my birthday], which was absent during the first written product. Additionally, the presentation of the lists of elements is more elaborated in the post than in the pre (i.e., "tacos, tostadas, arroz con habichuelas" [tacos, toasts, rice with beans] versus "me gusto los regalos, me gusto los juguetes y la ropa" [I liked the presents, I liked the toys and the clothes]. The analysis of these pre-post student products revealed no robust characteristics in relation to enhanced creativity. Both written pieces describe one context and include a general and simple picture. In both pre and post samples, the student enumerates elements of a sequence rather than elaborating in the story and including a variety of scenarios. The lack of creativity in the final products generated from students in the control group suggests that creativity, unless it is stimulated and valued, does not spontaneously increase as a result of students' schooling experiences. In fact, the results show that scores assigned to students' final products actually decreased in three measures of creativity (Complexity, Richness of Imagery, and Richness of Text).

Samples from students who participated in the pedagogical invitations revealed enhanced creativity as operationalized in terms of the described characteristics. Several representative sets of writing are presented below to convey the range of work produced in the class.

\section{Julia}

Figure 5 is an example of what we considered a complex final product.

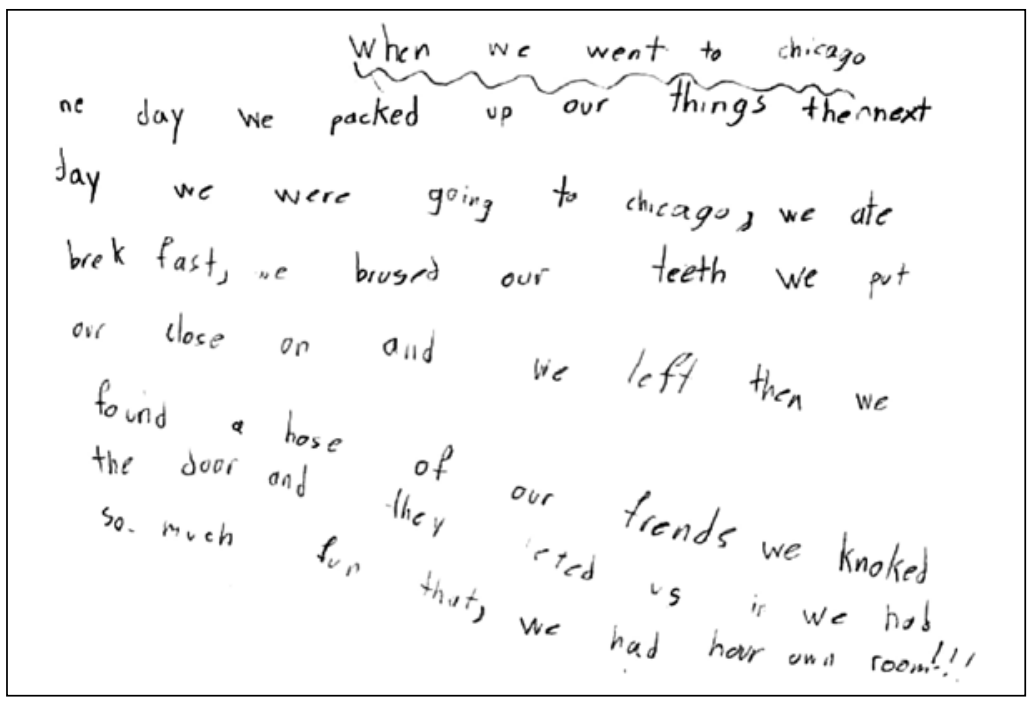




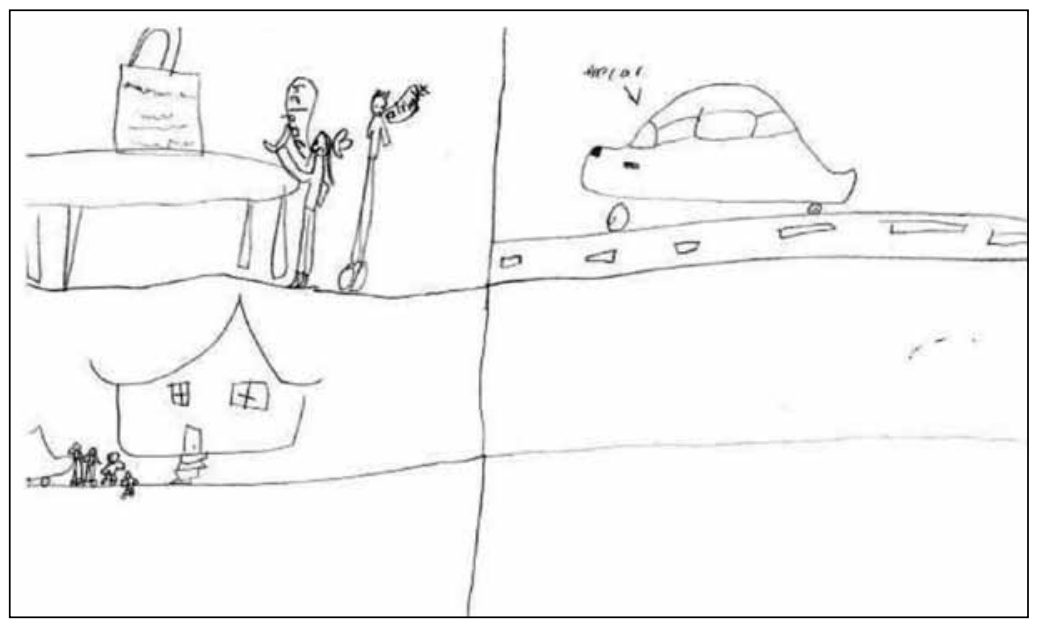

Fig. 5: Julia's post-instruction writing

Julia, the author of this piece, included a title and a story spanning three contexts (preparing for a trip, arriving at her friend's house, and her emotions once at the destination). Her work extended onto a second piece of paper, with visual representations of the story sequence. The first drawing corresponds to getting ready for the trip, and adds new elements to the written composition - a girl who appears to be the author saying "help me" while a taller figure, a family member, replies affirmatively. The second drawing shows their medium of transportation, and the final panel depicts four people arriving at a house. The white space on the page suggests that had Julia been given more time to complete the visual text, she may have included additional elements.

Comparing this final work with Julia's pre-instruction writing sample (Fig. 6), there is evidence of differences in complexity, and by extension, creativity.

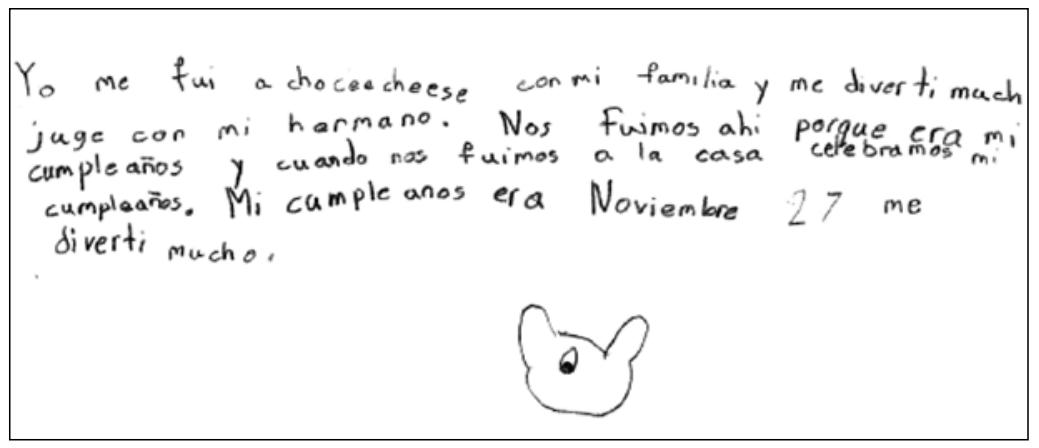

Fig. 6: Julia's pre-instruction writing 
The initial sample reads:

I went to Chuck E. Cheese with my family and I had a lot of fun I played with my brother. We went there because it was my birthday and when we went home we celebrated my birthday. My birthday was November 27 and I had a lot of fun [our translation].

While Julia also included here references to feeling/emotion, the pre-instruction writing piece contained fewer words than the post (42 versus 69), and elaborates on two contexts of the celebration (the arcade location and her home). Julia also included a drawing in this initial writing, but it is not as developed as that of her post-writing sample. We can assume it was intended to be a representation of the Chuck E. Cheese character, though it is in the early stages of completion. In comparison to the post drawing, this image is simpler and less developed, containing neither words nor multiple elements.

This difference in the complexity of the drawings and the integration of images and written text was present in the work of most of the children who participated in the biliteracy instruction. Contrary to the common assumption that as children learn more and become more sophisticated in their writing, they no longer need the support of drawing, we found that complex writings were enriched by progressively more complex drawings and that written and visual elements were highly integrated and complemented each other.

Carlos

The synergistic relationship between words and pictures holds even in cases where the writing does not initially appear more sophisticated, but where complexity is conveyed through the integration of written and visual text across scenarios. A representative example can be found in Carlos' pre (Fig. 7) and post (Fig. 8) writing samples. Juxtaposing these works reveals enhanced creativity following participation in the instructional sequence. 
Creative Literacies and Learning With Latino Emergent Bilinguals

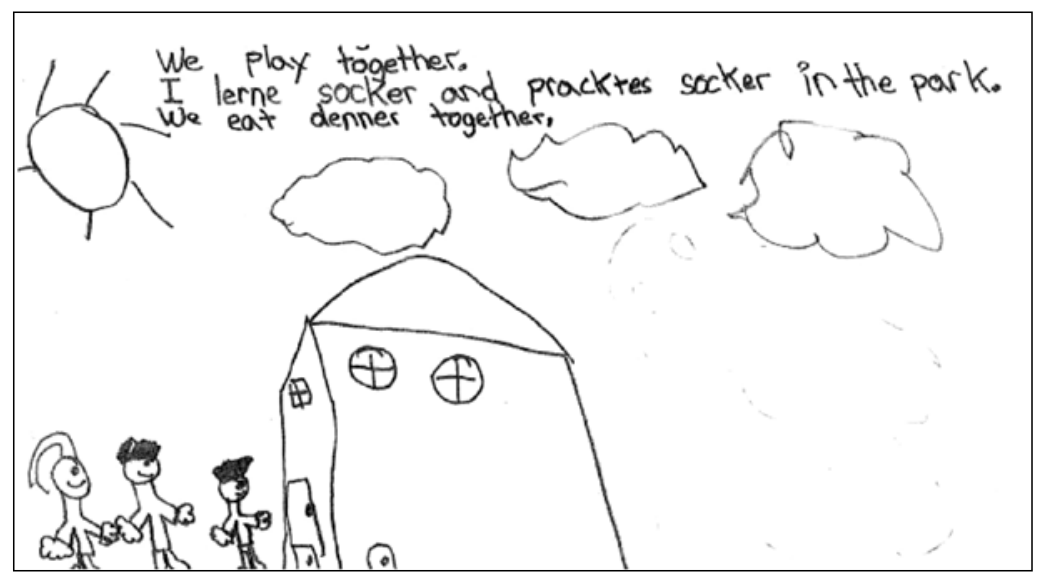

Fig. 7: Carlos' pre-instruction writing

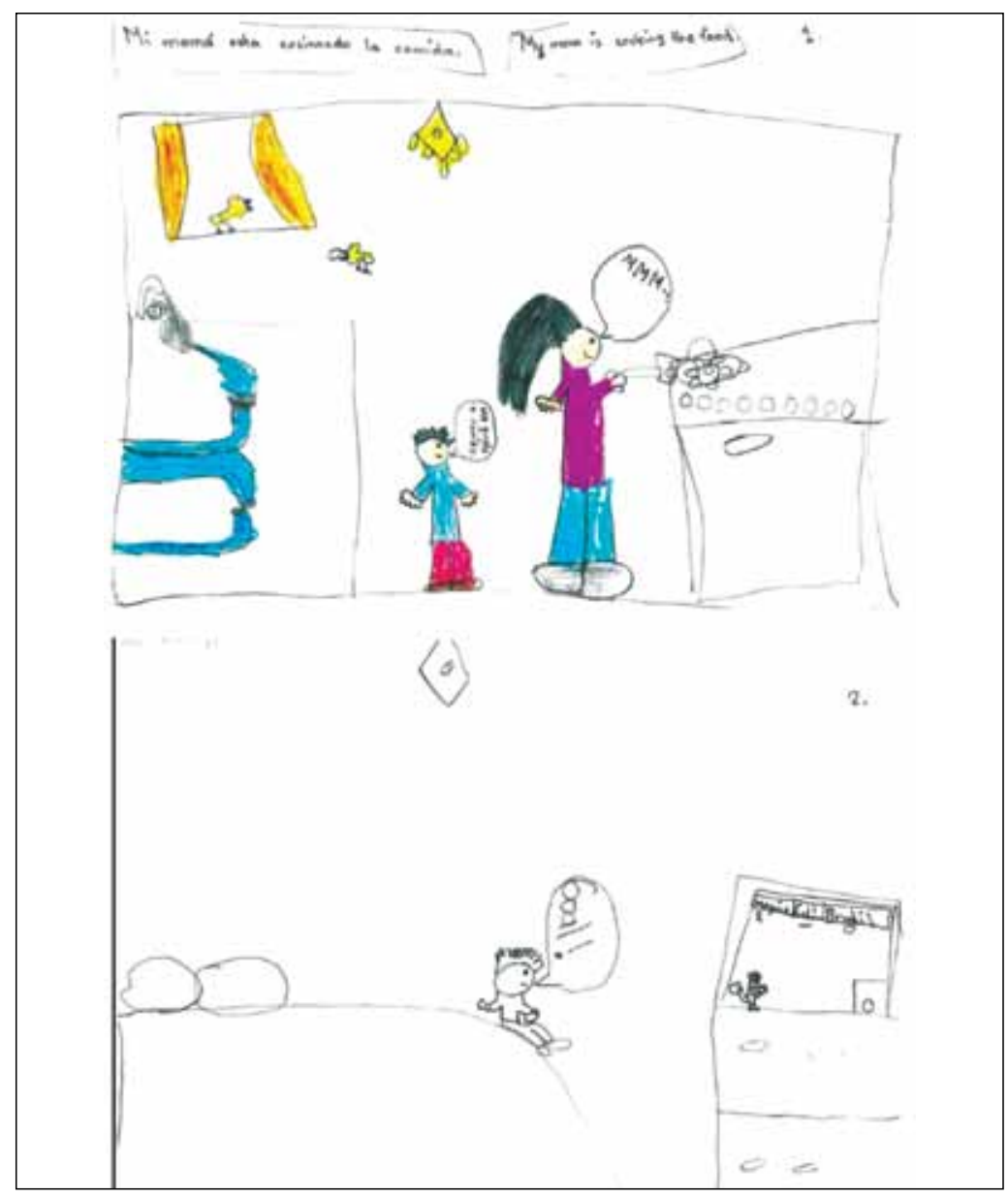

Fig. 8: Carlos' post-instruction writing

LEARNing Landscapes | Vol. 6, No. 1, Autumn 2012

289 
Carlos' pre-instruction writing presents a story on a singular piece of paper. He includes three complete sentences, and while both text and visuals are included, these dimensions appear only partially connected. By contrast, Carlos' post product includes two pieces with drawing and writing, which are closely connected. Atop the first page, he writes, "my mom is cooking the food" in both Spanish and English, an articulation which encapsulates the essence of that scene. The drawing below shows Carlos talking with his mom as she cooks. Carlos also included text within the illustration, extending the initial title/sentence as he explains, "I like food" in Spanish and his mom expresses how good the food is with "MMM..." The dialogue captures the interactive nature of the experience, rendered in the home language.

Carlos then moves his visual/written composition to a second page (carefully numbering at the top right-hand corner in the sequence), this time depicting himself watching a televised soccer game in another part of the home. The word "Goal!" uttered by the figure and the print on the tv screen "Megico[sic]: 2, Brazil: 0" and "Gol! [Goal!]" introduce important details. The two-piece work communicates important aspects of Latino culture, indexing both the particularities of Carlos' family and how they spend their time together, as well as broader cultural pastimes and even national allegiance, as Carlos cheers on his country's team. There is an innovative use of visuals to convey depth, as languages and traditions mix in Carlos' lived experience. Interestingly, the themes of soccer and family dinners are present in both the pre- and post-writing samples. However, through the integration of multiple languages and modes in the latter version, Carlos is able to create a more specific account of topics he considers important. Even the fact that Carlos chooses to pull out his crayons and include color is telling, since during more standardized writing experiences at the school such materials were off-limits.

\section{Jackson}

Another set of examples from a student in the instructional group provides an opportunity to unpack the affordances of biliteracy pedagogies that draw on children's languages and worlds through the use of multiple modes and media. Jackson's pre-instruction writing is shown in Figure 9 and the post-instruction writing is in Figure 10. 


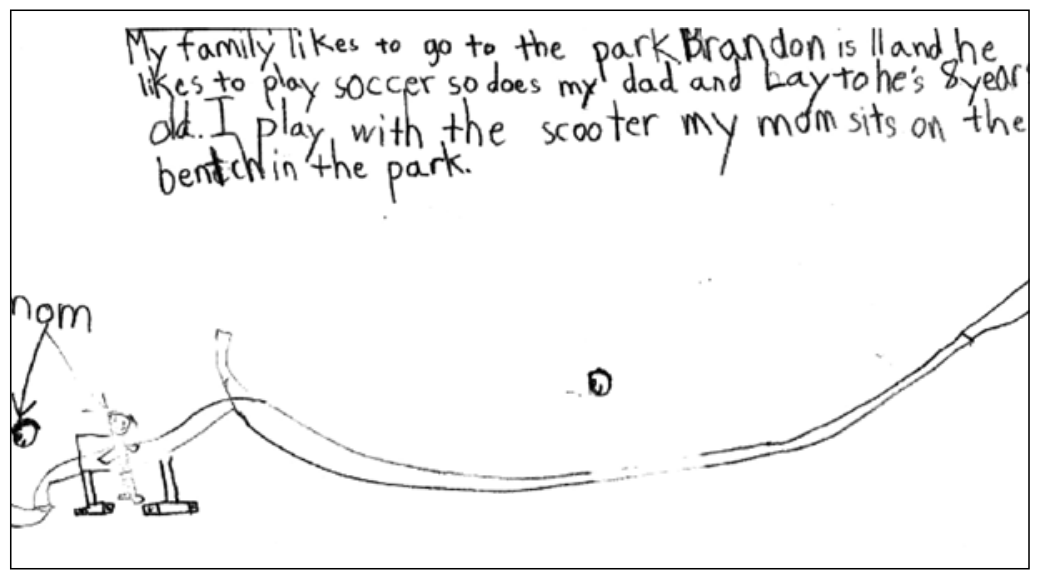

Fig. 9: Jackson's pre-instruction writing

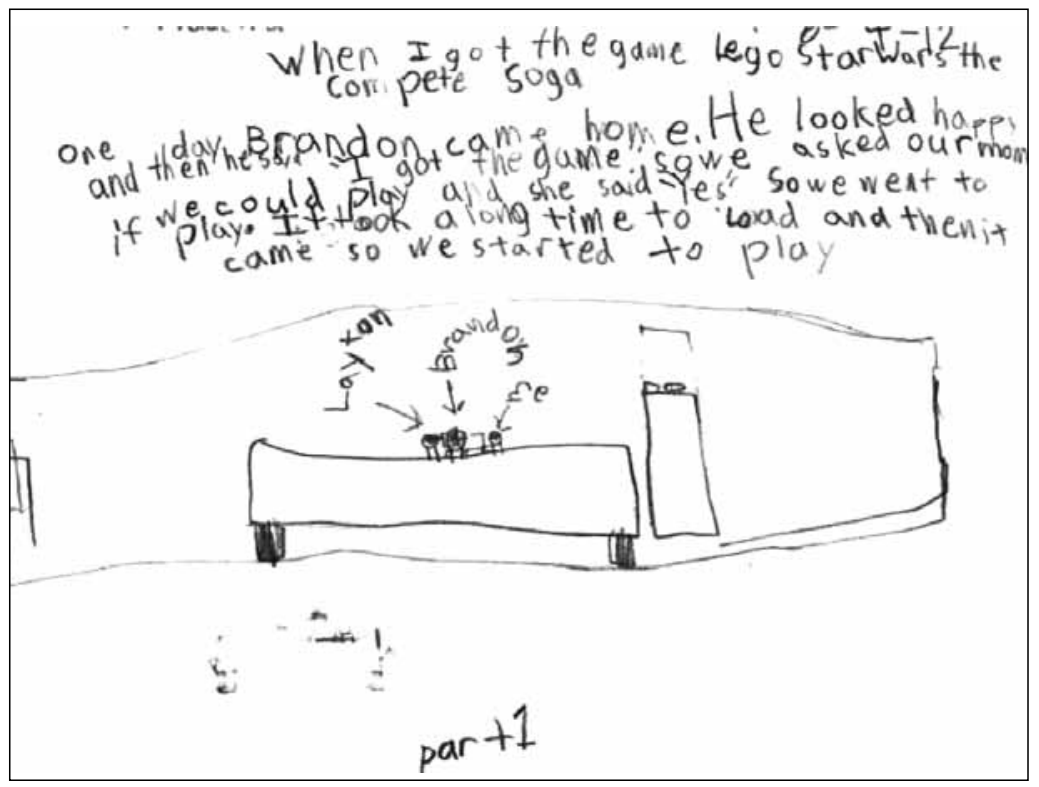

Fig. 10: Jackson's post-instruction writing 
Patricia Martínez-Álvarez, María Paula Ghiso, and Isabel Martínez

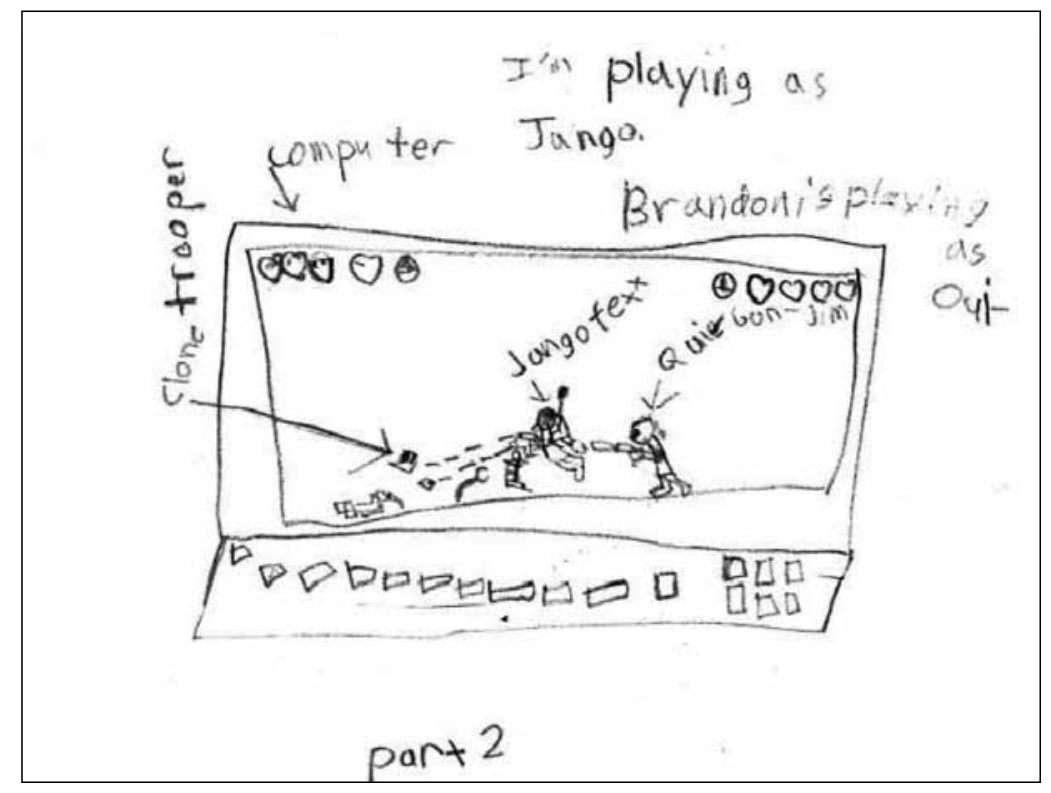

Wherrwe finished we played by our soles

part

Fig. 10: Jackson's post-instruction writing (cont.)

292

LEARNing Landscapes | Vol. 6, No. 1, Autumn 2012 
It is evident not only that Jackson wrote more in the final piece, but also how he manipulated verbal and visual text to create a multipart account that echoes features from other popular culture texts, such as movies and video games. The 10-word title synthesizes the three-page story with impressive vocabulary for a seven-yearold-“When I got the game Lego Star Wars: The Compete Soga [Saga]". Jackson's detailed description includes story language ("one day"), direct quotes, and connecting words such as "then" and "so." His visual text is not subsumed to the print, but extends the verbal account, providing details that would be difficult to convey with words alone. Part 2 begins with Jackson's identification of who is taking on the identity of each character in the video game ("I'm playing as Jango."). The visual image that dominates the page transports readers into the game itself, with labels denoting the characters, a battle taking place mid-screen, and icons at each corner denoting available lives and the remaining resources of each character. This rendering is complex yet efficient-what would take a great deal of space to describe in words is rendered visually in a way that conveys not only accuracy but also immediacy. Part 3 of Jackson's work includes a conclusion to the movie/book he had created. By contrast, Jackson's pre-writing more dichotomously separates verbal and visual modes, and does not exude the same level of enthusiasm for the topic represented.

\section{Towards Inclusive and Creative School Literacies}

Upon concluding our biliteracy study, we held a classroom celebration where the first graders could share their work, and were gratified by the overwhelming number of family members in attendance. This show of support is a testament to the possibility of creating school opportunities for learning that take seriously the value of family, and underscores the creative resources in the community that directly or indirectly inform the children's academic work. Our interviews with students regarding this project show that they possess a mature understanding, not always shared by teachers, of the importance of integrating family stories and community experiences into their schoolwork. The children made comments such as the following:

A mí me gustó hacer historias y dedicárselos a mi familia porque me recuerdo algunas veces de cuando estaba paseando con mi papá y mi mamá a la panadería y a lavar. [I liked making stories and dedicating them to my family because I remember times when I was walking with my mom and dad to the bakery and to do the washing]. 
A mí me pareció bien porque pude escribir todo de mi comunidad y mi familia porque creo que los lugares que visitamos son emocionantes y divertidos. [I liked it (the instruction) because I was able to write everything about my community and my family, because I think that the places we visit are exciting and fun].

Students continually expressed their excitement for the project and cheered whenever we handed out printed photographs, cartoon strips, scissors and glue, or computers as materials for composing beyond only paper and pencil.

In the current educational climate, bilingual learners are increasingly subjected to standardized curricula that homogenize experience (Campano, 2007) and reward sameness at the expense of individualized, self-directed learning. By participating in expansive school literacy activities that took seriously the value of their heritage, students were able to exercise agency in communicating aspects of their lives traditionally left outside the school curricula. Through photography, comics, digital texts, writing, drawing, and storytelling, children manipulated and blended multiple modes of expression to convey aspects of their identities they identified as important. Rather than passively hew to a delineated writing trajectory, the flexible opportunities for composing allowed students to be active designers (Kress, 2003) of texts, and created contexts of shared power in the classroom. The multimodal biliteracy pedagogies also resulted in more creative, complex, and personal representations than the traditional one-piece essays school requires children to write.

When students were given opportunities to blend their cultural and linguistic identities with their academic pursuits, and when the curriculum privileged children's choosing of how to represent their stories given an array of verbal and visual possibilities, they flourished creatively. Furthermore, even though such analysis and discussion are beyond the scope of this manuscript, we found evidence that students' literacy skills also improved in the participating group of students more than in the non-participating control group. Our findings suggest that cultural engagement, academic achievement, and creativity are not mutually exclusive, but may exist in a synergistic relationship. We encourage further studies to investigate this interconnection.

\section{Acknowledgments}

We would like to thank the journal editors, anonymous reviewers, and Gerald Campano for their insights on previous drafts of this article. 


\section{References}

Akinwamide, O.G., \& Adedara, O.G. (2012). Facilitating autonomy and creativity in second language learning through cybertasks, hyperlinks and net-surfing. English Language Teaching, 5(6), 36-43.

Akinwamide, T.K. (2007). Process approach and creativity in essay writing. Unpublished Doctoral Dissertation, AAUA, Nigeria.

Aljughaiman, A.M., \& Ayoub, A.E.A. (2012). The effect of an enrichment program on developing analytical, creative, and practical abilities of elementary gifted students. Journal for the Education of the Gifted, 35(2), 153-174.

Amabile, T.M. (1998). How to kill creativity. Harvard Business Review, 76(5), 76-87.

Antink Meyer, A. (2012). Teaching for creativity: Modify existing lessons and labs to promote creativity in your classroom. The Science Teacher, 79(5), 54-57.

Boden, M.A. (2001). Creativity and knowledge. In A. Craft, B. Jeffrey \& M. Leibling, (Eds.), Creativity in Education (pp. 95-102). London: Continuum.

Campano, G. (2007). Immigrant students and literacy: Reading, writing, and remembering. New York: Teachers College Press.

Campbell, D.T., \& Stanley, J.C. (1963). Experimental and quasi-experimental designs for research. Chicago: Rand-McNally.

Cochran-Smith, M., \& Lytle, S. (2009). Inquiry as stance: Practitioner research for the next generation. New York: Teachers College Press.

Cohen, J. (1960). A coefficient of agreement for nominal scales. Educational and Psychological Measurement, 20(1), 37-46.

Cummins, J. (2004). Multiliteracies pedagogy and the role of identity texts. In K. Leithwood, P. McAdie, N. Bascia, \& A. Rodigue (Eds.), Teaching for deep understanding: Towards the Ontario curriculum that we need (pp. 68-74). Toronto: OISE/ University of Toronto and the Elementary Federation of Teachers of Ontario.

Darder, A. (1995). Buscando America: The contributions of critical Latino educators to the academic development and empowerment of Latino students in the U.S. In C.E. Sleeter \& P.L. McLaren (Eds.) Multicultural Education, Critical Pedagogy and the Politics of Difference (pp. 319-348). New York: SUNY Press.

Denzin, N. (1978). The research act: $A$ theoretical introduction to sociological methods. New York: Editorial McGraw Hill.

Dixon-Krauss, L. (1996). Vygotsky in the classroom: Mediated literacy instruction and assessment. White Plains, NY: Longman.

Engeström, Y. (1987). Learning by expanding: An activity-theoretical approach to developmental research. Helsinki, SE: Orienta-Konsultit.

Engeström, Y., \& Sannino, A. (2010). Studies of expansive learning: Foundations, findings and future challenges. Educational Research Review, 5(1), 1-24.

Erickson, F. (1986). Qualitative methods in research on teaching. In Merlin C. Wittrock (Ed.), Handbook of research on teaching (pp. 119-161). New York: Macmillan.

Eyster, L. (2010). Encouraging creativity in the science lab. The Science Teacher, 77(6), 32-35.

Fleta Guillén, M.T., \& García Bermejo, M.L. (2011). Creative writing for language, content and literacy teaching. International Education, 4(5), 39-47.

Flores, B., Tefft-Cousin, P., \& Diaz, E. (1991). Transforming deficit myths about learning, language, and culture. Language Arts, 68, 369-378.

Fránquiz, M. E., \& de la Luz Reyes, M. (1998). Creating inclusive learning communities through English language arts: From chanclas to Canicas. Language Arts, 75(3), 211-220.

Freire, P. (1973). The pedagogy of the oppressed. New York: Seabury Press.

García, O. (2001). Bilingual education is beneficial. In M. E. Williams (Ed.), Education: Opposing Viewpoints (pp. 126-129). San Diego, CA: Greenhaven Press. 
García, O., \& Kleifgen, J. (2010). Educating emergent bilinguals: Policies, programs, and practices for English language learners. New York: Teachers College Press.

Geissler, G. L., Edison, S. W., \& Wayland, J. P. (2012). Improving students' critical thinking, creativity, and communication skills. Journal of Instructional Pedagogies, 8, 1-12.

Goff, K., \& Torrance, E.P. (2002). Abbreviated torrance test for adults. Bensenville, IL: Scholastic Testing Service.

Gutiérrez, K. (2008). Developing a sociocritical literacy in the Third Space. Reading Research Quarterly, 43(2), 148-164.

Hommel, B., Colzato, L.S., Fischer, R., \& Christoffels, I. (2011). Bilingualism and creativity: Benefits in convergent thinking come with losses in divergent thinking. Frontiers in Psychology, 2, 273.

Irby, B., \& Lara-Alecio, R. (1996). Attributes of Hispanic gifted bilingual students as perceived by bilingual educators in Texas. NYSABE Journal, 11, 120-142.

Kennedy, C. H. (2005). Single case designs for educational research. Boston: Allyn and Bacon.

Kharkhurin, A.V. (2007). The role of cross-linguistic and cross-cultural experiences in bilinguals' divergent thinking. In I. Kecskes \& L. Albertazzi (Eds.), Cognitive aspects of bilingualism (pp. 175-210). Dordrecht, the Netherlands: Springer.

Kharkhurin, A. V. (2010). Sociocultural differences in the relationship between bilingualism and creative potential. Journal of Cross-Cultural Psychology, 41, 776-783.

Kress, G. (2003). Literacy in the new media age. London: Routledge.

Landis, J.R., \& Koch, G.G. (1977). The measurement of observer agreement for categorical data. Biometrics 33, 159-174. doi:10.2307/2529310.

Lave, J., \& Wenger, E. (1991). Situated learning: Legitimate peripheral participation. Cambridge, UK: Cambridge University Press.
Lederman, N.G. (2007). Nature of science: Past, present, and future. In S.K. Abell \& N.G. Lederman (Eds.), Handbook of research on science education. New York: Routledge.

Medina, C., \& Campano, G. (2006). Performing identities through drama and teatro practices in multilingual classrooms. Language Arts, 83(4), 332-341.

Menken, K. (2008). English learners left behind: Standardized testing as language policy. Clevedon, UK: Multilingual Matters.

Moll, L.C. (1992). Bilingual classroom studies and community analysis. Educational Researcher, 21(2), 20-24.

Moll, L.C., Amanti, C., Neff, D., \& González, N. (1992). Funds of knowledge for teaching: Using a qualitative approach to connect homes and classrooms. Theory Into Practice, 31(2), 132-141.

National Advisory Committee on Creative and Cultural Education (NACCCE). (1999). All our futures: Creativity, culture, and education. Suffolk, DfEE.

Okoh, N. (1980). Bilingualism and divergent thinking among Nigerian and Welsh school children. Journal of Social Psychology, 110, 163-170.

Ricciardelli, L.A. (1992). Bilingualism and cognitive development in relation to threshold theory. Journal of Psycholinguistic Research, 21, 301-316.

Scribner, S., \& Cole, M. (1981). The psychology of literacy. Cambridge, MA: Harvard University Press.

Siegel, M. (2012). New times for Multimodality? Confronting the accountability culture. Journal of Adolescent \& Adult Literacy, 55(8), 671-681.

Strauss, A., \& Corbin, J. (1998). Basics of qualitative research techniques and procedures for developing grounded theory. 2nd edition. Thousand Oaks, CA: Sage.

Street, B. (1995). Social literacies: Critical approaches to literacy in development, ethnography, and education. London: Longman.

Vygotsky, L. S. (1997). Educational psychology. Boca Raton, FL: St. Lucie Press. 


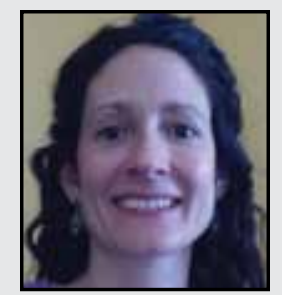

Patricia Martínez-Álvarez is a Visiting Assistant Professor in the Department of Arts and Humanities at Teachers College, Columbia University. Dr. Martínez-Álvarez is a former Arlington Public Schools dual language special education teacher. She has been an adjunct professor at George Mason University, Fairfax, VA, and a consultant with the Center for Applied Linguistics in a project focused on enhancing vocabulary through cognate awareness activities. Her scholarly interests focus on integrating language and science, and technologymediated learning in bilingual/bicultural settings. Patricia has conducted workshops with teachers in the United States and Perú. She has published in the field of interculturality, struggling learners, science conceptual change, and mobile and blended learning.

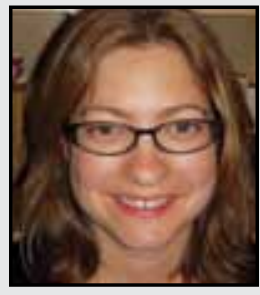

María Paula Ghiso is an Assistant Professor in the Department of Curriculum and Teaching at Teachers College, Columbia University. Her scholarly interests focus on two related strands: the critical literacy practices of young children, especially writing and response to literature, and language learning/biliteracy. María Paula has facilitated professional development in a range of national and international contexts, and is a former New York City dual language teacher. She has published in venues such as Language Arts, Handbook of Research on Children's and Young Adult Literature, Journal of Early Childhood Literacy, and the National Reading Conference Yearbook. 


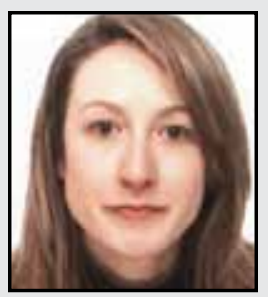

Isabel Martínez is a Developmental and Educational researcher at the Autónoma University of Madrid, Spain. Her research interests include the processes of reading and writing as learning tools at different educational levels. She is an active member of the COST Action ERN-LWE research group within the European Research Network on Learning to Write Effectively. The title of her dissertation is Teaching reading and writing to learn in Primary Education: design and evaluation of the efficacy of a program involving synthesis tasks from several source texts. She has published two articles based on the work she conducted through her doctoral period, and has fulfilled stays in two European countries outside of Spain.

\section{LINKTO:}

https://mason.gmu.edu/ pmartin5/portfolio/index.htm

http://www.tc.columbia.edu/academics/index.htm?facid=mpg2134 